\title{
Hidden diversity in Antarctica: molecular and morphological evidence of two different species within one of the most conspicuous ascidian species
}

\author{
Micaela Ruiz ${ }^{1}$, Anabela Taverna ${ }^{1}$, Natalia Servetto ${ }^{1}$, Ricardo Sahade ${ }^{1}$, and Christoph Held ${ }^{2}$ \\ ${ }^{1}$ Universidad Nacional de Cordoba \\ ${ }^{2}$ Alfred-Wegener Institute for Polar and Marine Research
}

May 5, 2020

\begin{abstract}
The Southern Ocean is one of the most isolated marine ecosystems, characterized by high levels of endemism, diversity, and biomass. Ascidians are among the dominant groups in Antarctic benthic assemblages, thus recording the evolutionary patterns of this group is crucial to improve our current understanding of the assembly of this polar ocean. We studied the genetic variation within Cnemidocarpa verrucosa sensu lato, one of the most widely distributed abundant and studied ascidian species in Antarctica. Using a mitochondrial and a nuclear gene (COI and 18S), the phylogeography of fifteen populations distributed along the Antarctic Peninsula and South America (Burdwood Bank/MPA Namuncurá) was characterized, where the bimodal distribution of the genetic distance suggested the existence of two species within the nominal C. verrucosa. When re-evaluating morphological traits to distinguish between genetically defined species, the presence of a basal disc in one of the genotypes could be a morphological trait to differentiate the species. These results are surprising due to the large research that has been carried out with the conspicuous C. verrucosa with no differentiation between species. Furthermore, it provides important tools to distinguish species in the field and laboratory. But also, these results give new insights to patterns of differentiation between closely related species that are distributed in sympatry, where the permeability of species boundaries still needs to be well understood.
\end{abstract}

\section{Introduction}

Triggered by a steep decline in atmospheric $\mathrm{CO}_{2}$, the Antarctic Polar Front (APF) has been working as a geographic, climatic, thermal and oceanographic barrier that isolated the Southern Ocean since the Eocene/Oligocene boundary, while the Antarctic Circumpolar Current (ACC) has been playing a role as disperser force around Antarctica (DeConto \& Pollard, 2003). Together with this, Antarctica and its Ocean suffered a series of glaciation cycles that fragmented its marine biota (Cristini, Grosfeld, Butzin, \& Lohmann, 2012; Hewitt, 2004; Petit et al., 1999; Soler-Membrives, Linse, Miller, \& Arango, 2017). In consequence, the Southern Ocean is one of the most diverse and rich marine ecosystems which presents a high level of endemism, even in comparison with temperate and tropical environments (Allcock \& Strugnell, 2012; Halanych \& Mahon, 2018; Rogers, 2007). Numerous cryptic species were discovered in this region, i.e. genetically distinct species that have been previously classified as a single species due to their similar phenotypes (Bickford et al., 2006; Held \& Wägele, 2005; Held, 2003). Therefore, the real species number in Antarctica would be higher than the registered today, and species yet undescribed represent an important portion of biodiversity (Dömel et al., 2015; Galaska, Sands, Santos, Mahon, \& Halanych, 2017; Havermans, Nagy, Sonet, De Broyer, \& Martin, 2011; Riesgo, Taboada, \& Avila, 2015; Wilson, Hunter, Lockhart, \& Halanych, 2007). Ascidians are an important group in the Antarctic benthic communities, being even dominant in some assemblages (Gili et al., 2006; Sahade, Tatián, Kowalke, Kühne, \& Esnal, 1998; Sahade et al., 2015). Cnemidocarpa verrucosa 
(Lesson, 1830) (Chordata, Tunicata) is the largest and most abundant Styelidae in the Antarctic Ocean, it shows circumpolar distribution in the Antarctic and is also distributed in the south of South America (Kott \& Mather, 1969; Monniot \& Monniot, 1983; Pineda, Turon, Pérez-Portela, \& López-Legentil, 2016). It can inhabit muddy to hard bottoms and waters between five to more than $500 \mathrm{~m}$ deep (Ramos-esplá, Cárcel, \& Varela, 2005; Tatián, Sahade, Doucet, \& Esnal, 1998). Cnemidocarpa verrucosa is hermaphroditic, possesses lecithotrophic larvae and strong seasonality in reproduction (Bowden, Clarke, \& Peck, 2009; Sahade, Tatián, \& Esnal, 2004; Strathmann, Kendall, \& Marsh, 2006).

The ascidian genome architecture has been demonstrated to be divergent from model organisms (small genome, transposon diversity, developmental gene stock, physical gene order, intron-exon organization, splicing patterns, and prevalence of single-exon 5'-genes operons), also there is circumstantial evidence that this group is characterized by an elevated rate of molecular and protein evolution (Dehal et al., 2002; Delsuc et al., 2018; Denoeud et al., 2010; Ganot, Kallesøe, Reinhardt, Chourrout, \& Thompson, 2004; Haubold, Pfaffelhuber, \& Lynch, 2010; Rubinstein et al., 2013; Satou et al., 2008). Furthermore, it has been demonstrated that hybridization and introgression take place among the closely related ascidians Ciona intestinalis and Ciona robusta. Hybridization was observed under field and lab conditions (Bouchemousse, Bishop, \& Viard, 2016; Sato, Shimeld, \& Bishop, 2014), and introgression was detected in sympatry zones, with nuclear (Jade) and also mitochondrial (COI) genes introgressed (Nydam, Giesbrecht, \& Stephenson, 2017a; Nydam \& Harrison, 2011). Hereafter, studying species delimitation in ascidians it is interesting since barriers to gene flow between species would be expected to be permeable.

Considering all the above mentioned, the goals of this work were, a) to determine if there are more than one genetically divergent species within the nominal C. verrucosa; b) to resolve if the presumable species are also morphologically distinguishable; c) to test if species within C. verrucosa co-occur; and if so, to test whether their co-occurrence can be explained by secondary contact and drifting by the ACC. To be able to recognize species in the face of high morphological variation, sympatry, potential hybridization, and introgression is the ultimate goal of this work. Furthermore, being able to discriminate species at the laboratory and also at the field may have implications in many research fields, especially in biodiversity and experimental studies.

\section{Materials and Methods}

\subsection{Sampling}

Specimens were collected during the campaign Mission Antarctique,on board the R/V Sedna IV in 2006, and the Summer Antarctic Campaigns in 2007/2008, by SCUBA diving between 20m and 30m depth; in the campaign BENTART-06, Antarctic Project of the "Bio Hespérides" (2006), the campaign ANT XXIX/3 in 2013, and the campaign PD BB April 17, on board the R/V A.R.A. Puerto Deseado in Burdwood Bank/MPA Namuncurá 2017 (BB/MPAN), the samples were obtained by bottom trawls nets at depths between $120 \mathrm{~m}$ and $138 \mathrm{~m}$. Fourteen sampling stations were distributed along the Antarctic Peninsula and one in South America in NMPA/BB (Fig. 3), the naming of sampling stations was done in the base of the SCAR Composite Gazetteer of Antarctica (last update 2014). The samples were conserved in denatured ethanol 96\% (Sigma-Aldrich, Argentina) until DNA extraction.

Samples for morphological analyses were collected in January 2018 by SCUBA diving between 20m and $30 \mathrm{~m}$ depth on soft substrate at Potter Cove (Carlini Station, King George Island, Antarctica). Twenty-three specimens were relaxed using menthol crystals (TodoDroga, Argentina), animals were placed in big trays and submerged in seawater, menthol crystals were placed inside the trays, after two hours a probe was inserted into an open siphon to check if there was absolutely no response If there was still a response the animals were kept there for another hour, after complete relaxation the animals were fixed in denatured ethanol 96\%. The examined material for morphological analyses is stored in the collection of the Museo de Zoología, Universidad Nacional de Córdoba, Argentina.

\subsection{DNA extraction, PCR and sequencing}

Total DNA was extracted from up to $25 \mathrm{mg}$ mantle muscle tissue using the DNeasy Mini Kit (Qiagen, 
Germany) according to the standard tissue protocol but reducing the final elution volume to 100ul. In order to obtain mantle tissue, dissection was carried out using sterilized forceps and scalpels, isolating the mantle from the rest of the tissues such as intestine and tunic.

Cytochrome c oxidase subunit I (COI) PCR. The tunicate primers pair Tun_reverse2 (Rev) (Stefaniak et al., 2009) and Cve-CO1-F54 (Fwd) 5' AGTGTTTTAATTCGAACAGA 3', and the primers pair Deg COI F2 (Fwd) and Deg COI R2 (Rev) (Reem, Douek, Paz, Katzir, \& Rinkevich, 2017) were used for amplification. The primer Cve-CO1-F54 (Fwd) was designed within this study as consequence of bad quality (double peaks, ill-defined or garbled peaks in the chromatograms) forward sequences obtained with the Stefaniak-primer, our primer was designed using the software Geneious version R8 (Kearse et al., 2012), and based on good quality forward sequences from this work. Reactions were carried out in $25 \mu \mathrm{l}$ volumes, using $0.025 \mathrm{U} / \mu \mathrm{l}$ of Promega GoTaq G2 Flexi DNA Polymerase, $30 \mathrm{ng}$ of DNA, $0.5 \mu \mathrm{M}$ of each primer and $2 \mathrm{mM}$ of $\mathrm{MgCl}_{2}$. The amplification protocol was $2 \mathrm{~min}$ at $94^{\circ} \mathrm{C}$ for initial denaturation followed by 36 cycles of $60 \mathrm{~s}$ at $94^{\circ} \mathrm{C}, 50 \mathrm{~s}$ at $46^{\circ} \mathrm{C}, 50 \mathrm{~s}$ at $72^{\circ} \mathrm{C}$, and a final elongation step of $8 \mathrm{~min}$ at $72^{\circ} \mathrm{C}$.

Nuclear Ribosomal RNA Gene (18S rDNA) PCR. Primers 18S1 (Fwd) and 18S4 (Rev) (Tsagkogeorga et al., 2009 ) were used for amplification. Reactions were carried out in $25 \mu \mathrm{l}$ volumes, using $0.03 \mathrm{U} / \mu \mathrm{l}$ of TaKaRa LA Taq HS, $30 \mathrm{ng}$ of DNA, $0.5 \mu \mathrm{M}$ of each primer and $0.05 \mathrm{mM}$ of Betaine. The amplification protocol was $1 \mathrm{~min}$ at $94^{\circ} \mathrm{C}$ for initial denaturation followed by 30 cycles of $10 \mathrm{~s}$ at $98^{\circ} \mathrm{C}, 50 \mathrm{~s}$ at $50^{\circ} \mathrm{C}, 2 \mathrm{~min}$ at $72^{\circ} \mathrm{C}$, and a final elongation step of $10 \mathrm{~min}$ at $72^{\circ} \mathrm{C}$.

PCR products were visualized on a $1 \%$ TAE agarose gel stained with GelRed (Nucleic Acid Gel Stain) under UV illumination. PCR products were outsourced for sequencing to Eurofins MWG Operon (Germany) on an ABI3730XL automatic DNA sequencer, using either of the two primers used for amplification.

\subsection{Sequence Alignment and Phylogenetic Analysis}

Nucleotide sequences were edited, assembled and aligned using the Muscle plugin (Edgar, 2004) within the program Codon Code Aligner (v. 5.1.5, Codon Code Corporation), primers sequences used for amplification were excluded from the analysis, COI sequences were translated into amino acid sequences based on the Ascidian mitochondrial code (translation table 13) to further improve sequencing quality and screen for frameshift mutations and stop codons.

Genetic polymorphism analysis was run for each population calculating the number of haplotypes (Nh), haplotype diversity (h) and nucleotide diversity ( $\pi$ ) using DnaSP version 5.10.01 (Librado \& Rozas, 2009). Sequences of 18S rDNA were phased with the PHASE v2.1.1 algorithm (Stephens \& Donnelly, 2003; Stephens, Smith, \& Donnelly, 2001) in DnaSP using default parameters. Pair-wise F $_{\text {ST }}$ among all populations and AMOVA were calculated using ARLEQUIN v. 3.5.2.2 (Excoffier, Laval, \& Schneider, 2005). The significance of the variance components and pairwise $\mathrm{F}_{\mathrm{ST}}$ values were assessed by a permutation test with 10,000 replicates. To test Isolation by distance in C. verrucosa populations, Mantel test with 1000 permutations was performed using IBD Macintosh application v. 1.52 (Bohonak, 2002). Scatter plot of geographical distance and genetic distance was performed in R. The genetic distances among populations were expressed as $\mathrm{F}_{\mathrm{ST}}$ pairwise differences. The geographical distances between populations were represented by the shortest coastline distance.

Species delimitation was carried out using the online version of Automatic Barcode Gap Discovery, ABGD (http://wwwabi.snv.jussieu.fr/public/abgd/) using Kimura p-distance. ABGD delimits a "barcode gap" in the distribution of pairwise differences (Puillandre, Lambert, Brouillet, \& Achaz, 2012). The haplotype network was created with the Haploviewer application (available at www.cibiv.at/ ${ }^{\mathrm{greg}} /$ haploviewer), based on multiple alignments of the sequences and on a neighbour joining tree that was constructed using the software MEGA 7.0.21 (Kumar, Stecher, Li, Knyaz, \& Tamura, 2018) using 500 bootstrap replicates and p-distance.

For phylogenetic reconstruction, the best fitting model was determined with the software jModeltest 2.1.9 v20160115, using Phyml v.3.0 with 88 candidate models. The best-fit model for COI was HKY85+G+ I, 
and for $18 \mathrm{~S}$ the best-fit model was HKY85+G+I, these substitutions models were applied in Maximum Likelihood (ML) and Bayesian Inference (BI) analysis. ML analysis was run using PhyML 3.0 (Guindon et al., 2010) using 1000 bootstrap replicates for both markers independently. BI analysis was run using sing Markov Chain Monte Carlo (MCMC) simulations in Mr. Bayes 3.2 (Ronquist et al., 2012), sampling every 100 generations, samples of the substitution model parameters were checked whether the likelihoods reaching stationarity, and weather the standard deviation of split frequencies was below 0.05. Mitochondrial COI reached stationarity with a total of 500000 MCMC generations (split=0.04), while $18 \mathrm{~S}$ with a total of 200000 MCMC generations (split=0.02). The remaining trees sampled were used to infer Bayesian posterior probabilities (BPP) at the nodes and produce the consensus tree.

In order to estimate divergence time since speciation, the BEAST 1.8.0 software package was used to analyse COI sequences (Drummond, Suchard, Xie, \& Rambaut, 2012). First, xml files were generated using BEAUti to execute them in BEAST. Data from other marine invertebrates were used as a proxy since due to lack of adequate fossil records, no calibrated mutation rates for ascidians for COI exist in the bibliography. Nydam and Harrison (2011) estimated from data based on other marine invertebrate taxa (crabs, shrimp, urchins), a mutation rate range of 0.016 to 0.026 substitutions per site / million years. Two independent analyses were run, a first one using strict clock model with a substitution rate of 0.016 substitutions per site / million years $\left(10^{7}\right.$ generations), and a second one at 0.026 substitutions per site / million years $\left(10^{7}\right.$ generations $)$, for both a burn-in of $20 \%$ was applied. The tree prior was set to Yule speciation. The GTR+G substitution model was used. The xml files were then executed in BEAST. Results were analysed using Tracer v1.6.0 to check the convergence to a stationary distribution of parameters.

\subsection{Morphological analysis}

A total of 23 specimens assumed to be the putative $C$. verrucosawere examined for morphological analyses. The samples were dissected, analysed and photographed using a stereoscopic microscope (Labomed CZM4 and CZM6) equipped with a digital camera for identification and documentation of internal characters. We analysed the principal external and internal morphological characters for Cnemidocarpa verrucosa(Lesson, 1830) following established procedures (Millar, 1960; Monniot \& Monniot, 1983; Turon, Cañete, Sellanes, Rocha, \& López-legentil, 2016). The external characteristics measured were: 1) position of the siphons (both terminal siphons on the same line on the distal part, or one of them oriented towards one side), 2) presence of basal disc, 3) shape of warts (rounded and smooth, or conical with multiple spine-like endings), 4) height, and 5) width. After dissection, following internal structures were noted: 1) number of oral tentacles; 2) total number of longitudinal vessels in folds of the branchial sac; 3) total number of longitudinal vessels between the folds of the branchial sac; 4) total number of gonads (left and right); and 5) number of stomach folds. Sequencing of COI and $18 \mathrm{~S}$ markers were carried out for these individuals in order to test the relationship between genetic and morphological grouping.

\subsection{Morphological data analysis}

A mixed data matrix was created with all morphological characters analysed. For multivariate analysis, a logarithmic transformation was made for quantitative variables (number of oral tentacles, number of longitudinal vessels in folds of the branchial sac, number of longitudinal vessels between the folds of the branchial sac, number of gonads and number of stomach folds). The height and width were not used for this analysis because these two characters are highly variable due to the elastic nature of the animal and the amount of water it contains. Nevertheless, correlation was tested among these two characters and the rest of the studied ones, and no significant relation was found (data not shown). Multivariate analyses were used to determine affinities between specimens of Cnemidocarpa verrucosa based on a morphological character matrix. Nonmetric multidimensional scaling (NMDS) was performed using three dimensions and Gower distance. Nonparametric multivariate analysis of variance (PERMANOVA) was used to assess differences between the groupings obtained in NMDS, each term of the analysis was tested using 9999 permutations. PAST 3.16 free statistical software was used for all the morphological data analyses (Hammer, Harper, \& Ryan, 2001). 


\section{Results}

\subsection{Cytochrome c oxidase subunit I (COI) and}

Nuclear Ribosomal RNA Gene (18S rDNA)

The aligned fragment of the COI gene was $503 \mathrm{bp}$ long excluding the amplification primers, in total 253 individuals from fourteen stations were sequenced successfully (https://doi.org/10.1594/PANGAEA.909707). The alignment does not contain gaps, translation of sequences to amino acid sequences revealed no frameshifts mutations or stop codons. The analysis of the sequences identified 28 haplotypes, 70 sites were polymorphic and 56 parsimony informative. The haplotype network (Fig. 1) showed two sharply distinct groups separated by 50 mutational steps. Group A is distributed all along the Antarctic Peninsula and shows two dominant haplotypes, Group B is distributed in Weddell Sea, Potter Cove, Palmer Station, Paradise Bay, and Rothera Station, again with two common haplotypes that are mainly present in Palmer Station. In addition, there are 18 rare haplotypes, represented by one or two individuals from a single location.

The aligned sequences from the $18 \mathrm{~S}$ fragment, containing the V4 ribosomal expansion segment, were 877 bp long. In total 312 individuals were sequenced, the alignment contained no gaps (https://doi.org/10.1594/PANGAEA.909707). We found 70 polymorphic sites, all parsimony informative, and after phase haplotype reconstruction, 10 haplotypes were recognized. From the 70 polymorphic informative sites, a single site at position 444 contained two variants that were congruent with the division among the mitochondrial groups A and B (Fig. 1). A single individual (collection code 291) showed both nucleotides (thymine and cytosine, respectively), this can be interpreted as 291 being heterozygous or hybrid (see discussion section 4.4).

The highest haplotype diversity for COI was in Potter Cove, but almost all the populations presented high values of diversity except for Livingston Island and the Scotia Sea. On the other hand, the highest haplotype diversity for $18 \mathrm{~S}$ was in Burdwood Bank/MPA Namuncurá, but also Potter Cove, the Scotia Sea and, Shetland L45 and L46 presented high diversity values (Supplemental information, Table 1). Sequencing of COI was not possible for some individuals, several pairs of primers were tested (Bishop et al., 2013; Folmer, Hoeh, Black, \& Vrijenhoek, 1994; Monniot, Dettai, Eleaume, Cruaud, \& Ameziane, 2011) with no successful amplification, possible reasons for this are discussed later (section 4.1).

\subsection{Species delimitation}

ABGD analysis showed a bimodal distribution in COI and 18S sequences pairwise differences. The genetic distance within each group for COI was $<1.00 \%$ whereas the genetic distance among groups was $>10.20 \%$ with no intermediate pairwise distances observed. ABGD analysis for $18 \mathrm{~S}$ sequences revealed genetic distance between within groups of $0.00 \%$, and genetic distance between groups $>3.00 \%$ again with no intermediate distances observed. The groups delimited using either of these methods were identical.

\subsection{Phylogenetic analysis and divergence time}

The phylogenetic trees based on both molecular markers (nuclear and mitochondrial), using the Maximum Likelihood and Bayesian Inference approach show two well-supported, reciprocally monophyletic and congruent groups of samples (posterior probability, PP [?] 0.99; bootstrap probability, BP = 99) (Fig. 2). Group "A" was more widely distributed along the Antarctic Peninsula, whereas group "B" was distributed in Weddell Sea, Potter Cove, Palmer Station, Paradise Bay, and Rothera Station. Moreover, the phylogeny built with the nuclear gene separated four extra groups; one cluster comprises exclusively individuals from Burdwood Bank/MPA Namuncura (PP 1, BP 100), a second group with two samples from Potter Cove (PP 1, BP 98), a third branch with only one sample from Burdwood Bank/MPA Namuncura, and a fourth group constituted by samples from Scotia Sea (PP 1, BP 99).

The two congruent clusters defined by the nuclear and mitochondrial phylogenetic trees were grouping the sequences in the same way as ABGD analysis and the haplotype network. However, two individuals were assigned to different groups depending on which marker was used, mitochondrial or nuclear. On one hand, 
the individual 291 from Potter Cove, was assigned to group A in 18S species delimitation, but to group B for COI. On the other hand, the individual 116 from Palmer Station was assigned to group B in 18S species delimitation, but to group A for COI. This crossed pattern is incompatible with congruent diversification of mitochondrial and nuclear genes, some hypothetical explanations for this result are discussed below (see discussion 4.4 section).

The estimation of divergence time among groups A and B, using COI sequences, was calculated between $3.58 \mathrm{Ma}$ (95\% High Posterior Density [HPD]: 2.331 - $4.935 \mathrm{Ma}$ ) and 2.20 Ma (95\% High Posterior Density [HPD]: $1.423-3.028 \mathrm{Ma})$.

\subsection{Morphological analysis}

The appearance of this species is characteristic: large, robust body, ovate or ellipsoidal. Usually, it is not compressed laterally. Specimens analysed were all sexually mature, and varied between $5.8 \mathrm{~cm}$ and $17.3 \mathrm{~cm}$ of length, and $4.1 \mathrm{~cm}$ and $9.6 \mathrm{~cm}$ of width. Siphons were located in the anterior part of the body; from 25 specimens only eight had siphons with different height. Ten specimens had a basal disc. The test, although hard, is usually quite thin and somewhat soft and flexible, of orange colour, brown or yellow in live specimens. In fixed specimens, the tunic was yellowish, brown or grey. Cnemidocarpa verrucosa is characterized by the presence of warts in the tunic. In this study, some specimens showed rounded and smooth warts, others presented conic with multiple spine-like ends warts, and some showed both types distributed in diverse ways on the tunic with no clear pattern, within the analysed specimens we found both types of warts. Internal characteristics represented the intraspecific variation previously described for this species: branchial sac had four folds in each side of the body, the number of longitudinal vessels in folds of the branchial sac ranged from 7 to 21 , the number of longitudinal vessels between the folds of the branchial sac ranged from 1 to 5 . The oral tentacles are filiform, alternating in size (short and long), the number ranged from 22 to 38 . The intestine was located on the middle-ventral left side of the body, there are from 19 to 30 stomach folds. The gonads were tubular, with an enclosing membrane, and were on the mantle. Specimens showed, in general, two gonads at each side of the body, nevertheless, specimens cv12 and cv16 presented two on the right side and one on the left side, cv23 showed one gonad on each side and cv25 two gonads in the right side. The distal end with gonoducts was directed toward the atrial siphon (raw data in https://doi.org/10.1594/PANGAEA.909707).

The NMDS showed two groups among samples (Supplemental information, Fig. S1). The two groups identified in the NMDS coincided with the specimens genetically identified as group A and B in the genetic analyses. PERMANOVA revealed significant differences between the groups conformed in NMDS analysis $(F=17.17 ; p=0.0001)$. All specimens from group B showed basal disc, while none of the specimens from group A did. Almost all individuals from genetic group A had a single type of wart, while the majority of the individuals from genetic group B had both types of warts (conical and smooth). None of the other morphological characters analysed in this study appeared to be phylogenetically informative.

\subsection{Population structure}

Given the results from genetic and morphological species delimitations (see above), it is highly likely that the two groups that were identified in nuclear, mitochondrial and morphological characters correspond to two reproductively isolated species inside nominal Cnemidocarpa verrucosa sensu lato, which in the following will be called C. verrucosa sp. A and C. verrucosa sp. B. Hence, the following analyses were carried out separately for each delimited species of $C$. verrucosa sensu stricto.

The overall fixation index for $C$. verrucosa sp. A (COI: $\mathrm{F}_{\mathrm{ST}}=0.072 ; \mathrm{p}<0.05 ; 18 \mathrm{~S}: \mathrm{F}_{\mathrm{ST}}=0.154 ; \mathrm{p}<$ 0.001) computed by AMOVA, pointed toward a high diversity and a strong structure among all Antarctic Peninsula sites (results from pairwise $\mathrm{F}_{\mathrm{ST}}$ genetic distance analysis for COI and 18S are shown in Table 2, Supplemental information).

On the other side, C. verrucosa sp. B showed no genetic structure among populations in COI-sequences pairwise $\mathrm{F}_{\mathrm{ST}}$ genetic distance analysis (Supplemental information, Table 3), and sequences from 18S nuclear gene presented all the same haplotype. AMOVA overall Fixation index for COI $\left(\mathrm{COI}: \mathrm{F}_{\mathrm{ST}}=0.003 ; \mathrm{p}>\right.$ 
0.05) also showed no genetic structure.

\section{Discussion}

In the present study, we show that the conspicuous and widespread in the Antarctic ascidian Cnemidocarpa verrucosa comprises two genetically divergent species distributed in sympatry along the Antarctic Peninsula. Moreover, results from Potter Cove populations suggest that the basal disc could be a morphological character to differentiate the two species.

\subsection{Two genetically divergent species}

Both molecular markers studied in this work (the mitochondrial COI and nuclear $18 \mathrm{~S}$ gene) distinguished two congruent groups, therefore there was strong evidence for recognising two genetically divergent species within C. verrucosa sensu lato populations from the Antarctic Peninsula: C. verrucosa sp. A and C. verrucosa sp. $B$. Nuclear and mitochondrial genes evolve independently because they differ in the mode of inheritance, ploidy, amount of recombination, introns number, mutation rate, repair mechanisms and effective population size (Hill, 2015). Thus, studying only one type of marker, can lead to a systematic bias in the inference of evolutionary processes (Ballard \& Whitlock, 2004). Such is the case of cichlid fish radiations in lakes of Africa, where different speciation patterns were addressed using only one type of marker (Seehausen et al., 2003). In this work both markers showed the same speciation pattern, which implies that both molecules were impacted in the same way by the same evolutionary mechanism, thus making strong the evidence for the mutually isolated gene pools.

Within the results obtained here, for some particular specimens no sequences were obtained of COI, while 18S nuclear gene could be sequenced. In this case, the phylogeny constructed with $18 \mathrm{~S}$ resolved basal branches that comprised clades that would present deeper genetic divergence with the rest of the animals, than the divergence among C. verrucosa sp. $A$ and sp. $B$ (see Fig. 2). Nuclear genes usually evolve at a slower rate compared to mitochondrial ones (Allio, Donega, Galtier, \& Nabholz, 2017; Havird \& Sloan, 2016). Furthermore, fast substitution rate and gene rearrangements were described for ascidians mitochondrial genome, and have been proposed to cause difficulties in standard polymerase chain reaction (PCR), because of mutations on the primer site (Delsuc et al., 2018; Denoeud et al., 2010; Gissi et al., 2010). Hereafter, the basal branches obtained in this study with $18 \mathrm{~S}$ sequences, composed by individuals from Burdwood Bank/MPA Namucura, Scotia Sea, Weddell Sea and Potter Cove (stations located in the tip of the Antarctic Peninsula and South America, see Fig. 3), could represent more distant species within C. verrucosa sensu lato, and be constituted by individuals in which the COI primer binding site has been mutated or rearranged.

Following with the effort of distinguishing genetic differentiated species, widely-adopted molecular markers, such as COI and 18S, are helpful to characterize unstudied groups (Hebert, Cywinska, Ball, \& deWaard, 2003). Here, applying ABGD method in COI and $18 \mathrm{~S}$ a barcode-gap, with no intermediate values, was found in the frequency distribution of the genetic differences between individuals of the putative C. verrucosa. This gap is observed when the divergence between organisms that belong to the same species is smaller than the divergence among organisms that belong to different species (Puillandre et al., 2012). Moreover, a robust approach for species delimitation is to compare genetic distances with related undisputed species pairs, given that the nucleotide substitution rate is quite homogeneous at interspecific level (Griggio et al., 2014; Held, 2003). In this study, the genetic distance between $C$. verrucosa sp. $A$ and $s p$. $B$ was $>10.20 \%$ for COI, and $>3 \%$ for $18 \mathrm{~S}$. The COI nucleotide divergence among ascidian species from the same genera range from $8.7 \%$ to 21.7\% (Hirose, Oka, \& Hirose, 2009; Nydam \& Harrison, 2007; Perez-Portela \& Turon, 2008), and between species within Styelidae family range from 10.8\% to 16.5\% (Lacoursiere-Roussel et al., 2012; Reem et al., 2017). Regarding $18 \mathrm{~S}$ gene, it has been found $0-0.58 \%$ nucleotide divergence among samples from genera Diplosoma. Furthermore, it has been described smaller divergence among the suborder of Diplosoma (Phlebobranchia) than among the suborder Stolidobranchia, in which C. verrucosa is described (Yokobori, Kurabayashi, Neilan, Maruyama, \& Hirose, 2006). Bock, Macisaac, and Cristescu (2012) found larger divergences (2.3 - 10.1\%) in 18S gene among putative cryptic species of Botryllus schlosseri ; important discussion exists on the definition of cryptic species within B.schlosseri but no study has confirmed yet a 
genetic and/or morphological evidence, therefore B. schlosseri is currently being treated as a species complex (Lejeusne, Bock, Therriault, MacIsaac, \& Cristescu, 2011; Nydam, Giesbrecht, \& Stephenson, 2017b; Reem et al., 2017; Yund, Collins, \& Johnson, 2015). On the other hand, Nydam and Harrison (2010) studied five nuclear loci in order to unravel the existence of two distinct forms ofCiona intestinalis, and found that Type A vs. Type B (recently defined by Brunetti et al. (2015) as two morphological and genetically different species) divergences range from 3.5 to $12.4 \%$. All this indicates that, within the samples studied here, the genetic differentiation was similar to those found in other species in the same family and other ascidians species pairs, therefore we can define two genetic divergent species based on mitochondrial as well as nuclear evidence.

\subsection{Two morphologically distinguishable species}

The genera Cnemidocarpa is described within the Styelidae (Ascidiacea) family (WoRMS, Shenkar et al., 2020) which presents highly variable morphological characters (Monniot, Monniot, \& Laboute, 1991). The Cnemidocarpa genus include solitary ascidians with thin but leathery tunic; gonads that could be elongated, tubular and occasionally ramified, always united in a compact mass contained within a membrane and attached to the body wall (Kott, 1985; Rocha, Zanata, \& Moreno, 2012). To distinguish the species within the genus one of the most used characteristics is the number of gonads at each side of the body, however, $C$. verrucosa presents a high variability from 1 to 4 gonads and in this work no significant variation was found in this character. A high variability on colour and shape of warts was observed in the studied specimens and in the field (Fig. 4), no other new or already described characters were found to discriminate between genetically different species. However, we found that the presence/absence of basal disc could be a possible diagnostic character for identifying two genetic species in Potter Cove (where both species coexist): all C. verrucosa sp. A specimens showed no basal disc, while C. verrucosa sp. B presented this structure. To define "basal disc" we followed Kott (1971) descriptions of C. verrucosa. In her work, it is reported a "stalk" posteriorly expanded basally where the animal is attached to the substrate, she described that the body wall prolongs into a muscle-free jelly-like extension that expands into a basal plate in the base of the stalk, this structure increase in thickness to form a sort of spherical rhizome, constricted off from the rest of the body. Tatian et al. (1998) already reported differences in stalk (basal disc in this study) development in C. verrucosa and Molgula pedunculata from Potter Cove. In their work, it was suggested that different substrate fixing requirements could determine the greater development of the stalk diameter in specimens of $C$. verrucosa from soft bottoms over those from hard bottoms. It was addressed in the literature that morphological differentiation of species depends on ecological/environmental factors and time since divergence (Fišer, Robinson, \& Malard, 2018; Harmon, Schulte II, Larson, \& Losos, 2003; Losos, 2008; Schluter, 2000). Our results suggest that the presence of the basal disc could be more related to genetically determined morphological differentiation than to phenotypic plasticity of the species. Nonetheless, to confirm this hypothesis it is necessary to address the genetic, morphological and spatial pattern of C. verrucosa sensu lato in a wider sampling range.

Morphological species delimitation is key, especially for recognition in the field when species are distributed in sympatry. Cnemidocarpa verrucosa was described initially by Lesson (1830), the type specimen was collected in Malvinas/Falklands Islands, in this and others descriptions the species was reported presenting high variability in shape, colour and size (Kott, 1971; Tatián, Antacli, \& Sahade, 2005; Turon et al., 2016), a pattern shared with others ascidians (Dias, Abreu, Silva, \& Solferini, 2008; Viard, Roby, Turon, Bouchemousse, \& Bishop, 2019; Wiernes, Sahade, Tatián, \& Chiappero, 2013). However, a character (morphological, molecular) may only appear to be polymorphic when two or more species are mistakenly treated as a single one. It is not uncommon that the apparent degree of polymorphism is strongly reduced once the cryptic or pseudo-cryptic species have been correctly identified (Dietz et al., 2015; Janosik \& Halanych, 2010; Korshunova, Martynov, Bakken, \& Picton, 2017; Montano, Maggioni, Galli, \& Hoeksema, 2017).

\subsection{Two species in sympatry}

Species C. verrucosa sp. A and C. verrucosasp. B are distributed in sympatry along the Antarctic Peninsula. Both species are present in the Weddell Sea, Scotia Sea, Potter Cove, Shetland L45, Palmer Station, Paradise 
Bay and Rothera Stations (Fig. 3). The absence of C. verrucosa sp. B in some sampling stations may be explained by the low number of samples obtained on those sites. Because both species coexist in sympatry but maintain genetic differences among them, a reproductive barrier must be playing an important role in isolating the species. Broadcast spawners, like C. verrucosa sensu lato, release gametes into the water column where fertilization occurs, thus the strength of the prezygotic reproductive barriers, like temporal isolation, can play a crucial role in reproductive isolation between species (Levitan et al., 2004). Another plausible hypothesis for reproductive isolation is gamete incompatibility, given that many studies on the evolution of gamete recognition proteins have shown that they tend to evolve more rapidly than other proteins, and frequently be under positive selection (Kosman \& Levitan, 2014; Vacquier \& Swanson, 2011). For example, in sea urchin species pairs, only 10 amino acid changes can lead to complete gamete incompatibility between species (Zigler, McCartney, Levitan, \& Lessios, 2005). According to this, to perform experiments of reproduction between $C$. verrucosa sp. $A$ and $s p$. $B$, would be helpful to understand the evolution and potential patterns of gene flow between these two closely related species.

The population structure of these species showed a striking and unexpected pattern, especially since they are sympatric and there are not significant known differences in biological, ecological or reproductive traits that could explain different dispersal potential.C. verrucosa sp. A showed genetic structured population, while no genetic structure was registered among the populations of $C$. verrucosa $s p$. B. Within $C$. verrucosa $s p$. $A$, IBD analysis showed no relation between genetic and geographic distance (Supplemental information, Fig. S2). C. verrucosa sensu lato presents a wide distribution range and with high registered abundances all around the Antarctic continent (Kott \& Mather, 1969; Monniot et al., 2011; Tatián et al., 1998; Tatián \& Lagger, 2010; Turon et al., 2016), thus the continuity and high abundance of populations could allow genetic connectivity, keeping an active gene flow over large distances. Therefore, and with no more current knowledge, it could be hypothesized that populations of $C$. verrucosa sp. B presents a more continuous distribution pattern along its distribution range allowing a higher gene flow, while C. verrucosa sp. A presents discrete populations with more restricted gene flow. Indeed, it has been suggested for ascidians that high mutation rates in both the nuclear and the mitochondrial genomes enable the accumulation of genetic diversity in relatively isolated populations (Delsuc, Brinkmann, Chourrout \& Philippe, 2006; Reem, Douek, Katzir \& Rinkevich, 2013). This, in turn, could be related to different capabilities for colonizing different substrate types, and/or to differential dispersal potential among the two species. Thus the reported capability of inhabiting all substrates of $C$. verrucosa sensu lato (Ramos-esplá et al., 2005; Tatian et al., 1998) would be mainly a $C$. verrucosa $B$ trait, and this species could present a longer larval stage and dispersal potential than its counterpart C. verrucosa sp. A. Despite been speculative hypothesis, they drive the attention to the fact that the reported variability on many biological and ecological traits for C. verrucosa sensu lato can be due to added characteristics of two species rather to an actual variability of the species.

\subsection{Incongruent mitochondrial/nuclear pattern}

An interesting pattern was observed when species delimitation was performed with both markers: two individuals were not assigned to the same group for both genes (we re-sequenced both genes and obtained unchanged results for both individuals). On one hand individual 291, was assigned to C. verrucosa sp. $A$ in $18 \mathrm{~S}$ species delimitation, but to $C$. verrucosa $s p . B$ for COI; on the other hand, individual 116, was assigned to C. verrucosasp. B in $18 \mathrm{~S}$ species delimitation, but to C. verrucosasp. A for COI. This means that only for these two specimens the nuclear and mitochondrial genes were addressing different speciation patterns. Apparent incongruence between phylogenies from $18 \mathrm{~S}$ and COI sequences was addressed already in ascidians by other authors (Pérez-Portela, Bishop, Davis \& Turon, 2009; Stach \& Turbeville, 2002). Even though in 18S sequences 70 polymorphic sites were found, only a single site was dividing the sequences into two groups that were congruent with mitochondrial and morphological inference, then other 69 variable sites were explaining intraspecific variability, or difference among the species (A and B) with four basal groups (see results section 3.3. and discussion section 4.1.). While C. verrucosa sp. A was characterized by a thymine in the unique variable site of $18 \mathrm{~S}$ sequences, C. verrucosa sp. B was characterized by a cytosine. Specimen 291 presented in this variable site two overlapped peaks (thymine and cytosine). This can be explained under two different assumptions, on the one hand, it can be expected that $C$. verrucosa $s p$. $A$ is characterized by a thymine 
in the unique variable site, but at the same time presents a low-frequency second allele; this allele carries a cytosine in the variable site, which would be predominant in the C. verrucosa sp. $B$. Thus, the individual 291 would be heterozygous. On top of this, it is also possible that with the primers that we used to sequence $18 \mathrm{~S}$ we sampled by PCR only a proportion of the allele population, and missed a group of molecules (null allele) that represents, for example, a heterozygote group of individuals. On the other hand, specimen 291 can be interpreted as a hybrid among C. verrucosa sp. $A$ and $s p . B$.

In order to explain the crossed pattern of these two specimens, some hypotheses can be considered: a) introgression, b) ancestral polymorphism with incomplete lineage sorting or c) convergent mutation. Hybridization and introgression patterns were already proposed in ascidians (Bouchemousse, Liautard-Haag, Bierne \& Viard, 2016; Nydam et al., 2017). Broadcast spawners present a reproductive system that has a higher probability of introgression/hybridization than others. Whilst artificial cross-fertilization among Ciona intestinalis Type A and B was demonstrated, hybrids remained infertile (Caputi et al., 2007; Sato et al., 2014). Once hybridization may occur, backcrossing with the parental types is more likely since genomes would be more similar than between species (Edmands, 2002). In this study, specimen 291 may represent the small population of hybrids among $C$. verrucosasp. $A$ and sp. $B$, while specimen 116 could be the result of an event of introgression, in which it might inherit allele A at COI from one parent and allele B at 18S from the other. In the same way, there is evidence of introgression within $C$. intestinalis Type A and $\mathrm{B}$, species that show high genetic divergence (12.4\%) at COI (Nydam \& Harrison, 2011; Nydam et al., 2017). These cryptic species, newly elevated to species status: $C$. intestinalis and $C$. robusta(Brunetti et al., 2015) show historical rates of gene flow, with almost complete absence of contemporary hybridization (Bouchemousse et al., 2016; Roux, Tsagkogeorga, Bierne, \& Galtier, 2013). This evidence supports the hypothesis of introgression within C. verrucosa sp. $A$ and sp. $B$ which presented, in this work, $10 \%$ genetic divergence at COI. Under those circumstances, it would be of interest to experimentally test hybridization among C. verrucosa $s p$. Aand $s p$. $B$. Ancestral polymorphism with incomplete lineage sorting (ILS) is another hypothesis that must be discussed under these results, it is difficult to distinguish this evolutionary process from introgression since both produce similar patterns. Discrepancies between trees inferred with mitochondrial and nuclear genes can be explained by these non-exclusive evolutionary hypotheses (Zhou et al., 2017). Nevertheless, bearing in mind the high genetic divergence among $C$. verrucosa sp. $A$ and $s p$. B, ILS is unlikely under neutral evolution (Pamilo \& Nei, 1988), since the loss of polymorphism and the fixation of an allele are positively correlated with time since divergence (Maddison, 1997; Wendel \& Doyle, 1998). There is circumstantial evidence that ascidians may be characterized by an elevated rate of molecular evolution (Delsuc et al., 2006). Therefore, a convergent mutation can also explain that individual 116 presents allele $\mathrm{B}$ in $18 \mathrm{~S}$, but being assigned to $C$. verrucosa sp. A for COI, given that the thymine mutates to a cytosine in the unique variable site.

\subsection{Timing and mode of speciation}

In order to estimate time since speciation, data from crabs, shrimps, and urchins were used as proxy (mutation rate range of 0.016 to 0.026 substitutions per site, per million years) (Nydam \& Harrison, 2011). Using this rates, we obtained the speciation of $C$. verrucosasp. $A$ and sp. $B$ at $3.58-2.20$ million years ago (MYA). Several estimations of whole-genome mutation rates have been calculated in ascidians pointing out the rapid evolution of this group (Berna \& Alvarez-Valin, 2014; Denoeud et al., 2010), but not specifically for mitochondrial genome, which typically evolves faster than the nuclear genome (Havird \& Sloan, 2016). On average ascidian evolutionary whole-genome rate in terms of number of substitutions per million years is 6.25 times faster than vertebrates, and 2.08 faster than cephalochordates (Delsuc et al., 2018). This indicates that, even though we can estimate the speciation time based on other marine invertebrate taxa data, we should bear in mind that we may be overestimating the time since divergence and that the range of time since speciation proposed here would be an older limit with the actual speciation time likely being more recent. We can hypothesize that speciation took place after the Miocene or later, when Antarctica already experienced the cooling process (Zachos, Pagani, Sloan, Thomas \& Billups, 2001). A summary of the evolutionary patterns in Antarctic organisms based on other studies reported radiation and speciation processes by 8-5 MYA; and cycles of population concentration, isolation in refugia and expansion, speciation and transoceanic dispersal by 1 MYA (Rogers, 2007). Some examples of these processes in Antarctic taxa are arthropods, annelids, 
echinoderms and molluscs (Baird, Miller, \& Stark, 2011; Hemery et al., 2012; Linse, Cope, Lörz, \& Sands, 2007; Raupach et al., 2010; Riesgo et al., 2015; Wilson et al., 2007). Then, a similar pattern of allopatric speciation followed by secondary contact can be attributed to C. verrucosa (Mayr, 1963). On the other hand, speciation in response to ecological opportunity (Simpson, 1953) can also be hypothesized with our results. Under this type of speciation, a new trait evolves and affects the ecological versatility of the specimens (Givnish et al., 2014; Liem, 1973). In this case, the development of a basal disc could represent an adaptive character for colonizing different substrates.

\section{Conclusions}

This work provides new insights to understand the evolution of molecules and morphology at the same time. The evidence presented here allowed to delimitate two species within C. verrucosa : two monophyletic groups were obtained; congruent mitochondrial, nuclear species delimitation was demonstrated. The magnitude of difference between the two distinguished species was similar to those among undisputed species pairs, and both species were distributed in sympatry. Morphological analysis suggests that the presence of a basal disc could be a morphological feature distinguishing the species. Nominal C. verrucosa sensu lato are distributed all around Antarctica and in the south of South America. However, the true extent of the species distribution area is obscured by the existence of two, possibly more species that have up until now been mistaken as a single species. Incongruent mitochondrial-nuclear phylogenies might be explained by different hypotheses as introgression/hybridization or ILS. Boundaries between sympatric species are maintained by barriers to gene flow, these restrictions may not be uniform in space, time or across the genome. In fact, it has been proposed that these barriers are semipermeable and speciation under gene flow is possible (Nosil, 2008). Further analysis employing several nuclear loci and an extended geographical sampling, would help to elucidate the evolutionary story of this broadly distributed Antarctic ascidian species. Patterns regarding genetic and morphological differentiation that are being underestimated or not registered systematically, can lead to important misunderstanding of species distribution patterns related to adaptation, habitat preference, competition and response to climate change. Our results once again emphasize that species identities, even for highly abundant and well-studied species on small local scales, must be assessed rather than assumed.

\section{List of abbreviations}

ABGD: Automatic barcode gap

APF: Antarctic Polar Front

ILS: Incomplete lineage sorting

ACC: Antarctic circumpolar current

MYA: Million years ago

\section{Acknowledgements}

The authors want to particularly thank the members of the Carlini (former Jubany) - Dallmann staff and Andrea Eschbach for kind assistance in laboratory work. Logistic and financial support was provided by Instituto Antártico Argentino (IAA), Alfred Wegener Institute (AWI), CONICET, IMCONet [FP7 IRSES (International Research Staff Exchange Scheme), action no. 319718], Short Term Grant 2019 Scholarship of Deutscher Akademischer Austauschdienst [German Academic Exchange Service (DAAD) Reference number: 91701637], and Lerner-Gray Memorial Fund of the American Museum of Natural History. The authors are grateful to the crew of the R/V "Puerto Deseado" and Gisela Morán for help in sampling. This work was partially supported by the Área Marina Protegida Namuncurá (Ley 26.875). Particular thank to Marcos Tatián who provided scientific support and guidance in the morphological analysis, and Cristian Lagger who provided the underwater photos.

\section{References}


Allcock, A. L., \& Strugnell, J. M. (2012). Southern Ocean diversity: new paradigms from molecular ecology. Trends in Ecology 83 Evolution, 27 (9), 520-528.

Allio, R., Donega, S., Galtier, N., \& Nabholz, B. (2017). Large variation in the ratio of mitochondrial to nuclear mutation rate across animals: Implications for genetic diversity and the use of mitochondrial DNA as a molecular marker. Molecular Biology and Evolution ,34 (11), 2762-2772. https://doi.org/10.1093/molbev/msx197

Baird, H. P., Miller, K. J., \& Stark, J. S. (2011). Evidence of hidden biodiversity, ongoing speciation and diverse patterns of genetic structure in giant Antarctic amphipods. Molecular Ecology ,20 (16), 3439-3454.

Ballard, J. W. O., \& Whitlock, M. C. (2004). The incomplete natural history of mitochondria. Molecular Ecology , 13 (4), 729-744. https://doi.org/10.1046/j.1365-294X.2003.02063.x

Berna, L., \& Alvarez-Valin, F. (2014). Evolutionary genomics of fast evolving tunicates. Genome Biology and Evolution , 6 (7), 1724-1738. https://doi.org/10.1093/gbe/evu122

Bickford, D., Lohman, D. J., Sodhi, N. S., Ng, P. K. L., Meier, R., Winker, K., ... Das, I. (2006). Cryptic species as a window on diversity and conservation. Trends in Ecology and Evolution ,22 (3), 148-155. https://doi.org/10.1016/j.tree.2006.11.004

Bishop, J. D. D., Roby, C., Yunnie, A. L. E., Wood, C. A., Lévêque, L., Turon, X., \& Viard, F. (2013). The Southern Hemisphere ascidian Asterocarpa humilis is unrecognised but widely established in NW France and Great Britain. Biological Invasions , 15 (2), 253-260.

Bock, D. G., Macisaac, H. J., \& Cristescu, M. E. (2012). Multilocus genetic analyses differentiate between widespread and spatially restricted cryptic species in a model ascidian. Proceedings of the Royal Society B: Biological Sciences , 279 (1737), 2377-2385. https://doi.org/10.1098/rspb.2011.2610

Bohonak, A. J. (2002). IBD (isolation by distance): a program for analyses of isolation by distance. Journal of Heredity ,93 (2), 153-154.

Bouchemousse, S., Bishop, J. D. D., \& Viard, F. (2016). Contrasting global genetic patterns in two biologically similar, widespread and invasive Ciona species (Tunicata, Ascidiacea). Scientific Reports , 6 (April). https://doi.org/10.1038/srep24875

Bouchemousse, S., Liautard-Haag, C., Bierne, N., \& Viard, F. (2016). Distinguishing contemporary hybridization from past introgression with postgenomic ancestry-informative SNPs in strongly differentiated Ciona species. Molecular Ecology , 25 (21), 5527-5542. https://doi.org/10.1111/mec.13854

Bowden, D. A., Clarke, A., \& Peck, L. S. (2009). Seasonal variation in the diversity and abundance of pelagic larvae of Antarctic marine invertebrates. Marine Biology , 156 (10), 2033-2047. https://doi.org/10.1007/s00227-009-1235-9

Brunetti, R., Gissi, C., Pennati, R., Caicci, F., Gasparini, F., \& Manni, L. (2015). Morphological evidence that the molecularly determined Ciona intestinalis type A and type B are different species: Ciona robusta and Ciona intestinalis. Journal of Zoological Systematics and Evolutionary Research , 53 (3), 186-193. https://doi.org/10.1111/jzs.12101

Caputi, L., Andreakis, N., Mastrototaro, F., Cirino, P., Vassillo, M., \& Sordino, P. (2007). Cryptic speciation in a model invertebrate chordate. Proceedings of the National Academy of Sciences ,104 (22), 9364-9369. https://doi.org/10.1073/pnas.0610158104

Cristini, L., Grosfeld, K., Butzin, M., \& Lohmann, G. (2012). Influence of the opening of the Drake Passage on the Cenozoic Antarctic Ice Sheet: A modeling approach. Palaeogeography, Palaeoclimatology, Palaeoecology , 339 -341 , 66-73. https://doi.org/10.1016/j.palaeo.2012.04.023

Dehal, P., Satou, Y., Campbell, R. K., Chapman, J., Degnan, B., De Tomaso, A., .. Rokhsar, D. S. (2002). The draft genome of Ciona intestinalis: Insights into chordate and vertebrate origins.Science , 298 (5601), 
2157-2167. https://doi.org/10.1126/science.1080049

Delsuc, F., Brinkmann, H., Chourrout, D., \& Philippe, H. (2006). Tunicates and not cephalochordates are the closest living relatives of vertebrates. Nature , 439 (7079), 965-968. https://doi.org/10.1038/nature04336

Delsuc, F., Philippe, H., Tsagkogeorga, G., Simion, P., Tilak, M. K., Turon, X., .. Douzery, E. J. P. (2018). A phylogenomic framework and timescale for comparative studies of tunicates. BMC Biology ,16 (1), 1-14. https://doi.org/10.1186/s12915-018-0499-2

Denoeud, F., Henriet, S., Mungpakdee, S., Aury, J. M., Da Silva, C., Brinkmann, H., ... Chourrout, D. (2010). Plasticity of animal genome architecture unmasked by rapid evolution of a pelagic tunicate.Science , 330 (6009), 1381-1385. https://doi.org/10.1126/science.1194167

Dias, G. M., Abreu, A. G., Silva, F. de O. M., \& Solferini, V. N. (2008). Microgeographical differentiation between morphotypes of Trididemnum orbiculatum (Tunicata: Ascidiacea) in Southeastern Brazil.Aquatic Biology , 4 (3), 243-252. https://doi.org/10.3354/ab00115

Dietz, L., Arango, C. P., Dömel, J. S., Halanych, K. M., Harder, A. M., Held, C., .. Rouse, G. W. (2015). Regional differentiation and extensive hybridization between mitochondrial clades of the Southern Ocean giant sea spider Colossendeis megalonyx. Royal Society Open Science , 2 (7), 140424.

Dömel, J. S., Harder, A. M., Melzer, R. R., Arango, C. P., Held, C., Mayer, C., .. Wilson, N. G. (2015). Regional differentiation and extensive hybridization between mitochondrial clades of the Southern Ocean giant sea spider Colossendeis megalonyx . Royal Society Open Science , 2 (7), 140424. https://doi.org/10.1098/rsos.140424

Drummond, A. J., Suchard, M. A., Xie, D., \& Rambaut, A. (2012). Bayesian phylogenetics with BEAUti and the BEAST 1.7. Molecular Biology and Evolution, 29 (8), 1969-1973.

Edgar, R. C. (2004). MUSCLE: multiple sequence alignment with high accuracy and high throughput. Nucleic Acids Research ,32 (5), 1792-1797.

Edmands, S. (2002). Does parental divergence predict reproductive compatibility? Trends in Ecology and Evolution , 17 (11), 520-527. https://doi.org/10.1016/S0169-5347(02)02585-5

Excoffier, L., Laval, G., \& Schneider, S. (2005). Arlequin (version 3.0): an integrated software package for population genetics data analysis. Evolutionary Bioinformatics , 1, 117693430500100000.

Fišer, C., Robinson, C. T., \& Malard, F. (2018). Cryptic species as a window into the paradigm shift of the species concept. Molecular Ecology , 27 (3), 613-635. https://doi.org/10.1111/mec.14486

Folmer, O., Hoeh, W. R., Black, M. B., \& Vrijenhoek, R. C. (1994). Conserved primers for PCR amplification of mitochondrial DNA from different invertebrate phyla. Molecular Marine Biology and Biotechnology , 3 , 294-299.

Galaska, M. P., Sands, C. J., Santos, S. R., Mahon, A. R., \& Halanych, K. M. (2017). Geographic structure in the Southern Ocean circumpolar brittle star Ophionotus victoriae (Ophiuridae) revealed from mt DNA and single-nucleotide polymorphism data. Ecology and Evolution ,7 (2), 475-485.

Ganot, P., Kallesøe, T., Reinhardt, R., Chourrout, D., \& Thompson, E. M. (2004). with a Compact Genome +. Society , 24 (17), 7795-7805. https://doi.org/10.1128/MCB.24.17.7795

Gili, J. M., Arntz, W. E., Palanques, A., Orejas, C., Clarke, A., Dayton, P. K., .. Lopez-Gonzalez, P. J. (2006). A unique assemblage of epibenthic sessile suspension feeders with archaic features in the high-Antarctic. Deep-Sea Research Part II: Topical Studies in Oceanography , 53 (8-10), 1029-1052. https://doi.org/10.1016/j.dsr2.2005.10.021

Gissi, C., Pesole, G., Mastrototaro, F., Iannelli, F., Guida, V., \& Griggio, F. (2010). Hypervariability of ascidian mitochondrial gene order: Exposing the Myth of deuterostome organelle genome stability.Molecular 
Biology and Evolution , 27 (2), 211-215. https://doi.org/10.1093/molbev/msp234

Givnish, T. J., Barfuss, M. H. J., Van Ee, B., Riina, R., Schulte, K., Horres, R., .. Smith, J. A. C. (2014). Adaptive radiation, correlated and contingent evolution, and net species diversification in Bromeliaceae. Molecular Phylogenetics and Evolution, 71, 55-78.

Griggio, F., Voskoboynik, A., Iannelli, F., Justy, F., Tilak, M. K., Xavier, T., ... Gissi, C. (2014). Ascidian mitogenomics: Comparison of evolutionary rates in closely related taxa provides evidence of ongoing speciation events. Genome Biology and Evolution ,6 (3), 591-605. https://doi.org/10.1093/gbe/evu041

Guindon, S., Dufayard, J.-F., Lefort, V., Anisimova, M., Hordijk, W., \& Gascuel, O. (2010). New algorithms and methods to estimate maximum-likelihood phylogenies: assessing the performance of PhyML 3.0. Systematic Biology, 59 (3), 307-321.

Halanych, K. M., \& Mahon, A. R. (2018). Challenging dogma concerning biogeographic patterns of Antarctica and the Southern Ocean.Annual Review of Ecology, Evolution, and Systematics , 49 , 355-378.

Hammer, O., Harper, D. A. T., \& Ryan, P. D. (2001). PAST: paleontological statistics software package for education and data analysis. Palaeontologia Electronica , 4 (1), 9.

Harmon, L. J., Schulte II, J. A., Larson, A., \& Losos, J. B. (2003). Tempo and Mode of Evolutionary Radiation in Iguanian Lizards $\backslash \mathrm{r} 10.1126 /$ science.1084786. Science ,301 (5635), 961-964. Retrieved from http://www.sciencemag.org/cgi/content/abstract/301/5635/961

Haubold, B., Pfaffelhuber, P., \& Lynch, M. (2010). MlRho - A program for estimating the population mutation and recombination rates from shotgunsequenced diploid genomes. Molecular Ecology ,19 (SUPPL. 1), 277-284. https://doi.org/10.1111/j.1365-294X.2009.04482.x

Havermans, C., Nagy, Z. T., Sonet, G., De Broyer, C., \& Martin, P. (2011). DNA barcoding reveals new insights into the diversity of Antarctic species of Orchomene sensu lato (Crustacea: Amphipoda: Lysianassoidea). Deep Sea Research Part II: Topical Studies in Oceanography , 58 (1-2), 230-241.

Havird, J. C., \& Sloan, D. B. (2016). The roles of mutation, selection, and expression in determining relative rates of evolution in mitochondrial versus nuclear genomes. Molecular Biology and Evolution , 33 (12), 3042-3053. https://doi.org/10.1093/molbev/msw185

Hebert, P. D. N., Cywinska, A., Ball, S. L., \& deWaard, J. R. (2003). Biological identifications through DNA barcodes. Proceedings. Biological Sciences / The Royal Society , 270 (1512), 313-321. https://doi.org/10.1098/rspb.2002.2218

Held, Christoph, \& Wagele, J.-W. (2005). Cryptic speciation in the giant Antarctic isopod Glyptonotus antarcticus (Isopoda: Valvifera: Chaetiliidae). Scientia Marina , 69 (2), 175-181. https://doi.org/10.3989/scimar.2005.69s2175

Held, Chrostoph. (2003). Molecular evidence for cryptic speciation within the widespread Antarctic crustacean Ceratoserolis trilobitoides (Crustacea, Isopoda). Antarctic Biology in a Global Context, Proceedings , 3 (Kattner 1998), 135-139 338.

Hemery, L. G., Eleaume, M., Roussel, V., Ameziane, N., Gallut, C., Steinke, D., ... Wilson, N. G. (2012). Comprehensive sampling reveals circumpolarity and sympatry in seven mitochondrial lineages of the Southern Ocean crinoid species Promachocrinus kerguelensis (Echinodermata). Molecular Ecology , 21 (10), $2502-2518$.

Hewitt, G. M. (2004). Genetic consequences of climatic oscillations in the Quaternary. Philosophical Transactions of the Royal Society of London. Series B, Biological Sciences , 359 (1442), 183-195; discussion 195. https://doi.org/10.1098/rstb.2003.1388

Hill, G. E. (2015). Mitonuclear ecology. Molecular Biology and Evolution , 32 (8), 1917-1927. https://doi.org/10.1093/molbev/msv104 
Hirose, E., Oka, A. T., \& Hirose, M. (2009). Two new species of photosymbiotic ascidians of the genus Diplosoma from the Ryukyu Archipelago, with partial sequences of the COI gene. Zoological Science , 26 (5), 362-368. https://doi.org/10.2108/zsj.26.362

Janosik, A. M., \& Halanych, K. M. (2010). Unrecognized Antarctic biodiversity: a case study of the genus Odontaster (Odontasteridae; Asteroidea). Integrative and Comparative Biology , 50 (6), 981-992.

Kearse, M., Moir, R., Wilson, A., Stones-Havas, S., Cheung, M., Sturrock, S., .. Duran, C. (2012). Geneious Basic: an integrated and extendable desktop software platform for the organization and analysis of sequence data. Bioinformatics , 28 (12), 1647-1649.

Korshunova, T., Martynov, A., Bakken, T., \& Picton, B. (2017). External diversity is restrained by internal conservatism: new nudibranch mollusc contributes to the cryptic species problem. Zoologica Scripta, 46 (6), 683-692.

Kosman, E. T., \& Levitan, D. R. (2014). Sperm competition and the evolution of gametic compatibility in externally fertilizing taxa.Molecular Human Reproduction , 20 (12), 1190-1197.

Kott, P. (1971). Antarctic Ascidiacea II. Biology of the Antarctic Seas IV , 17, 11-82.

Kott, P. (1985). The Australian ascidiacea part IP, Phlebobranchia and Stolidobranchia. Mem. Qd Mus. , 23.

Kott, P., \& Mather, P. (1969). Antarctic Ascidiacea: Monographic Account of the Known Species Based on Specimens Collected Under US Government Auspices, 1947-1965 (Vol. 13). American Geophysical Union.

Kumar, S., Stecher, G., Li, M., Knyaz, C., \& Tamura, K. (2018). MEGA X: molecular evolutionary genetics analysis across computing platforms. Molecular Biology and Evolution , 35 (6), 1547-1549.

Lacoursiere-Roussel, A., Bock, D. G., Cristescu, M. E., Guichard, F., Girard, P., Legendre, P., \& McKindsey, C. W. (2012). Disentangling invasion processes in a dynamic shipping-boating network. Molecular Ecology , 21 (17), 4227-4241. https://doi.org/10.1111/j.1365-294X.2012.05702.x

Lejeusne, C., Bock, D. G., Therriault, T. W., MacIsaac, H. J., \& Cristescu, M. E. (2011). Comparative phylogeography of two colonial ascidians reveals contrasting invasion histories in North America.Biological Invasions , 13 (3), 635-650. https://doi.org/10.1007/s10530-010-9854-0

Levitan, D. R., McGhee, K. E., Swanson, C. A., Fukami, H., Jara, J., Kline, D., .. McGovern, T. M. (2004). Mechanisms of reproductive isolation among sympatric broadcast-spawning corals of the Montastraea annularis species complex. Evolution , 58 (2), 308-323. https://doi.org/10.1111/j.0014-3820.2004.tb01647.x

Librado, P., \& Rozas, J. (2009). DnaSP v5: A software for comprehensive analysis of DNA polymorphism data. Bioinformatics , 25 (11), 1451-1452. https://doi.org/10.1093/bioinformatics/btp187

Liem, K. F. (1973). Evolutionary strategies and morphological innovations: cichlid pharyngeal jaws. Systematic Zoology ,22 (4), 425-441.

Linse, K., Cope, T., Lorz, A.-N., \& Sands, C. (2007). Is the Scotia Sea a centre of Antarctic marine diversification? Some evidence of cryptic speciation in the circum-Antarctic bivalve Lissarca notorcadensis (Arcoidea: Philobryidae). Polar Biology , 30 (8), 1059-1068.

Losos, J. B. (2008). Phylogenetic niche conservatism, phylogenetic signal and the relationship between phylogenetic relatedness and ecological similarity among species. Ecology Letters ,11 (10), 995-1003. https://doi.org/10.1111/j.1461-0248.2008.01229.x

Maddison, W. P. (1997). Gene trees in species trees. Systematic Biology , 46 (3), 523-536.

Mayr, E. (1963). Animal species and evolution. Animal Species and Evolution. 
Millar, R. H. (1960). The identity of the ascidians Styela mammiculata Carlisle and S. clava Herdman. Journal of the Marine Biological Association of the United Kingdom , 39 (3), 509-511.

Monniot, C., \& Monniot, F. (1983). Ascidies antarctiques et subantarctiques: morphologie et biogeographie . Editions du Museum.

Monniot, C., Monniot, F., \& Laboute, P. (1991). Coral reef ascidians of New Caledonia . IRD Editions.

Monniot, F., Dettai, A., Eleaume, M., Cruaud, C., \& Ameziane, N. (2011). Antarctic Ascidians (Tunicata) of the French-Australian survey CEAMARC in Terre Adelie. Zootaxa , 2817 (1), 1-54.

Montano, S., Maggioni, D., Galli, P., \& Hoeksema, B. W. (2017). A cryptic species in the Pteroclava krempfi species complex (Hydrozoa, Cladocorynidae) revealed in the Caribbean. Marine Biodiversity ,47 (1), 83-89.

Nosil, P. (2008). Speciation with gene flow could be common.Molecular Ecology , 17 (9), 2103-2106.

Nydam, M. L., Giesbrecht, K. B., \& Stephenson, E. E. (2017a). Origin and dispersal history of two colonial ascidian clades in the Botryllus schlosseri species complex. PLoS ONE , 12 (1), 1-30. https://doi.org/10.1371/journal.pone.0169944

Nydam, M. L., Giesbrecht, K. B., \& Stephenson, E. E. (2017b). Origin and dispersal history of two colonial ascidian clades in the Botryllus schlosseri species complex. PLoS ONE , 12 (1), 1-30. https://doi.org/10.1371/journal.pone.0169944

Nydam, M. L., \& Harrison, R. G. (2007). Genealogical relationships within and among shallow-water Ciona species (Ascidiacea). Marine Biology , 151 (5), 1839-1847. https://doi.org/10.1007/s00227-007-0617-0

Nydam, M. L., \& Harrison, R. G. (2010). Polymorphism and divergence within the ascidian genus Ciona. Molecular Phylogenetics and Evolution , 56 (2), 718-726. https://doi.org/10.1016/j.ympev.2010.03.042

Nydam, M. L., \& Harrison, R. G. (2011). Introgression despite substantial divergence in a broadcast spawning marine invertebrate.Evolution , 65 (2), 429-442. https://doi.org/10.1111/j.1558-5646.2010.01153.x

Nydam, M. L., Yanckello, L. M., Bialik, S. B., Giesbrecht, K. B., Nation, G. K., Peak, J. L., \& Marcos, S. (2017). Introgression in two species of broadcast spawning marine invertebrate, 879-890.

Pamilo, P., \& Nei, M. (1988). Relationships between gene trees and species trees. Molecular Biology and Evolution , 5 (5), 568-583.

Perez-Portela, R., Bishop, J. D. D., Davis, A. R., \& Turon, X. (2009). Phylogeny of the families Pyuridae and Styelidae (Stolidobranchiata, Ascidiacea) inferred from mitochondrial and nuclear DNA sequences. Molecular Phylogenetics and Evolution, 50 (3), 560-570. https://doi.org/10.1016/j.ympev.2008.11.014

Perez-Portela, Rocio, \& Turon, X. (2008). Cryptic divergence and strong population structure in the colonial invertebrate Pycnoclavella communis (Ascidiacea) inferred from molecular data. Zoology ,111 (2), 163-178. https://doi.org/10.1016/j.zool.2007.06.006

Petit, R. J., Raynaud, D., Basile, I., Chappellaz, J., Ritz, C., Delmotte, M., .. Pe, L. (1999). Climate and atmospheric history of the past 420,000 years from the Vostok ice core, Antarctica.Nature , 399 , 429-413. https://doi.org/10.1038/20859

Pineda, M. C., Turon, X., Perez-Portela, R., \& Lopez-Legentil, S. (2016). Stable populations in unstable habitats: temporal genetic structure of the introduced ascidian Styela plicata in North Carolina.Marine Biology , 163 (3), 1-14. https://doi.org/10.1007/s00227-016-2829-7

Puillandre, N., Lambert, A., Brouillet, S., \& Achaz, G. (2012). ABGD, Automatic Barcode Gap Discovery for primary species delimitation.Molecular Ecology , 21 (8), 1864-1877. https://doi.org/10.1111/j.1365294X.2011.05239.x 
Ramos-espla, A. a, Carcel, J. a, \& Varela, M. (2005). Zoogeographical relationships of the littoral ascidiofauna around the Antarctic Peninsula, in the Scotia Arc and in the Magellan region. Scentia Marina , 69 , 215-223. https://doi.org/10.3989/scimar.2005.69s2215

Raupach, M. J., Thatje, S., Dambach, J., Rehm, P., Misof, B., \& Leese, F. (2010). Genetic homogeneity and circum-Antarctic distribution of two benthic shrimp species of the Southern Ocean, Chorismus antarcticus and Nematocarcinus lanceopes. Marine Biology , 157 (8), 1783-1797.

Reem, E., Douek, J., Katzir, G., \& Rinkevich, B. (2013). Long-term population genetic structure of an invasive urochordate: The ascidian Botryllus schlosseri. Biological Invasions , 15 (1), 225-241. https://doi.org/10.1007/s10530-012-0281-2

Reem, E., Douek, J., Paz, G., Katzir, G., \& Rinkevich, B. (2017). Phylogenetics, biogeography and population genetics of the ascidian Botryllus schlosseri in the Mediterranean Sea and beyond.Molecular Phylogenetics and Evolution , 107 , 221-231. https://doi.org/10.1016/j.ympev.2016.10.005

Riesgo, A., Taboada, S., \& Avila, C. (2015). Evolutionary patterns in Antarctic marine invertebrates: An update on molecular studies.Marine Genomics , 23 , 1-13. https://doi.org/10.1016/j.margen.2015.07.005

Rocha, R. M. da, Zanata, T. B., \& Moreno, T. R. (2012). Keys for the identification of families and genera of Atlantic shallow water ascidians. Biota Neotropica , 12 (1), 269-303.

Rogers, A. D. (2007). Evolution and Biodiversity of Antarctic Organisms: A Molecular Perspective. Antarctic Ecosystems: An Extreme Environment in a Changing World , (May), 417-467. https://doi.org/10.1002/9781444347241.ch14

Ronquist, F., Teslenko, M., Van Der Mark, P., Ayres, D. L., Darling, A., Hohna, S., .. Huelsenbeck, J. P. (2012). MrBayes 3.2: efficient Bayesian phylogenetic inference and model choice across a large model space. Systematic Biology , 61 (3), 539-542.

Roux, C., Tsagkogeorga, G., Bierne, N., \& Galtier, N. (2013). Crossing the species barrier: genomic hotspots of introgression between two highly divergent Ciona intestinalis species. Molecular Biology and Evolution, 30 (7), 1574-1587.

Rubinstein, N. D., Feldstein, T., Shenkar, N., Botero-Castro, F., Griggio, F., Mastrototaro, F., ... Huchon, D. (2013). Deep sequencing of mixed total DNA without barcodes allows efficient assembly of highly plastic Ascidian mitochondrial genomes. Genome Biology and Evolution , 5 (6), 1185-1199. https://doi.org/10.1093/gbe/evt081

Sahade, Ricaerdo, Tatian, M., Kowalke, J., Kuhne, S., \& Esnal, G. B. (1998). Benthic faunal associations on soft substrates at Potter Cove, King George Island, Antarctica. Polar Biology , 19 (2), 85-91.

Sahade, Ricardo, Tatian, M., \& Esnal, G. (2004). Reproductive ecology of the ascidian Cnemidocarpa verrucosa at Potter Cove, South Shetland Islands, Antarctica. Marine Ecology Progress Series ,272 (Clarke 1988), 131-140. https://doi.org/10.3354/meps272131

Sato, A., Shimeld, S. M., \& Bishop, J. D. D. (2014). Symmetrical reproductive compatibility of two species in the Ciona intestinalis (Ascidiacea) species complex, a model for marine genomics and developmental biology. Zoological Science, 31 (6), 369-374.

Satou, Y., Mineta, K., Ogasawara, M., Sasakura, Y., Shoguchi, E., Ueno, K., .. Inaba, K. (2008). Improved genome assembly and evidence-based global gene model set for the chordate Ciona intestinalis: New insight into intron and operon populations. Genome Biology , 9 (10), 1-11. https://doi.org/10.1186/gb-2008-9-10r152

Schluter, D. (2000). Ecological Character Displacement in Adaptive Radiation. The American Naturalist, 156 (4), S4-S16. https://doi.org/https://doi.org/10.1086/303412 
Seehausen, O., Koetsier, E., Schneider, M. V., Chapman, L. J., Chapman, C. A., Knight, M. E., ... Bills, R. (2003). Nuclear markers reveal unexpected genetic variation and a Congolese-Nilotic origin of the Lake Victoria cichlid species flock. Proceedings of the Royal Society B: Biological Sciences , 270 (1511), 129-137. https://doi.org/10.1098/rspb.2002.2153

Simpson, G. G. (1953). The major features of evolution .

Soler-Membrives, A., Linse, K., Miller, K. J., \& Arango, C. P. (2017). Genetic signature of last glacial maximum regional refugia in a circum-antarctic sea spider. Royal Society Open Science, 4 (10). https://doi.org/10.1098/rsos.170615

Stach, T., \& Turbeville, J. M. (2002). Phylogeny of Tunicata inferred from molecular and morphological characters. Molecular Phylogenetics and Evolution , 25 (3), 408-428. https://doi.org/Pii S1055-7903(02)00305-6

Stefaniak, L., Lambert, G., Gittenberger, A., Zhang, H., Lin, S., \& Whitlatch, R. B. (2009). Genetic conspecificity of the worldwide populations of Didemnum vexillum Kott, 2002. Aquatic Invasions ,4 (1), 87-94. https://doi.org/10.3391/ai. 2009.4.1.3

Stephens, M., \& Donnelly, P. (2003). A comparison of bayesian methods for haplotype reconstruction from population genotype data. The American Journal of Human Genetics , 73 (5), 1162-1169.

Stephens, M., Smith, N. J., \& Donnelly, P. (2001). A new statistical method for haplotype reconstruction from population data. The American Journal of Human Genetics , 68 (4), 978-989.

Strathmann, R. R., Kendall, L. R., \& Marsh, A. G. (2006). Embryonic and larval development of a cold adapted Antarctic ascidian. Polar Biology, 29 (6), 495-501. https://doi.org/10.1007/s00300-005-0080-7

Tatian, M., Sahade, R. J., Doucet, M. E., \& Esnal, G. B. (1998). Ascidians (Tunicata, Ascidiacea) of Potter Cove, South Shetland Islands, Antarctica. Antarctic Science , 10 (2), 147-152. https://doi.org/10.1017/s0954102098000194

Tatian, M, \& Lagger, C. (2010). Ascidiacea-Ascidians. Marine Benthic Fauna of Chilean Patagonia. Nature in Focus, Puerto Montt .

Tatian, M, Sahade, R. J., Doucet, M. E., \& Esnal, G. B. (1998). Ascidians (Tunicata, Ascidiacea) of Potter Cove, South Shetland Islands, Antarctica. Antarctic Science , 10 (02), 147-152. https://doi.org/10.1017/S0954102098000194

Tatian, Marcos, Antacli, J. C., \& Sahade, R. (2005). Ascidians (Tunicata, Ascidiacea): species distribution along the Scotia Arc.Scientia Marina , 69 (S2), 205-214. https://doi.org/10.3989/scimar.2005.69s2205

Tsagkogeorga, G., Turon, X., Hopcroft, R. R., Tilak, M.-K., Feldstein, T., Shenkar, N., .. Delsuc, F. (2009). An updated $18 \mathrm{~S}$ rRNA phylogeny of tunicates based on mixture and secondary structure models. $B M C$ Evolutionary Biology , 9 (1), 187. https://doi.org/10.1186/1471-2148-9-187

Turon, X., Canete, J. I., Sellanes, J., Rocha, R. M., \& Lopez-legentil, S. (2016). Too cold for invasions? Contrasting patterns of native and introduced ascidians in subantarctic and temperate Chile.Management of Biological Invasions , 7 (1), 77-86. https://doi.org/10.3391/mbi.2016.7.1.10

Turon, X., Canete, J. I., Sellanes, J., Rocha, R. M., \& Lopez-Legentil, S. (2016). Ascidian fauna (Tunicata, Ascidiacea) of subantarctic and temperate regions of Chile Millenium Nucleus for Ecology and Sustainable Management of Oceanic Islands (ESMOI), Chile. Zootaxa ,4093 (2), 151-180. https://doi.org/10.11646/zootaxa.4093.2.1

Vacquier, V. D., \& Swanson, W. J. (2011). Selection in the rapid evolution of gamete recognition proteins in marine invertebrates. Cold Spring Harbor Perspectives in Biology , 3 (11), a002931.

Viard, F., Roby, C., Turon, X., Bouchemousse, S., \& Bishop, J. (2019). Cryptic diversity and database errors challenge non-indigenous species surveys: an illustration with Botrylloides spp. in the English Channel and 
Mediterranean Sea. Frontiers in Marine Science , 6 , 615.

Wendel, J. F., \& Doyle, J. J. (1998). Phylogenetic incongruence: window into genome history and molecular evolution. In Molecular systematics of plants II (pp. 265-296). Springer.

Wiernes, M. P., Sahade, R., Tatian, M., \& Chiappero, M. B. (2013). Genetic variability and differentiation among polymorphic populations of the genus Synoicum (Tunicata, Ascidiacea) from the South Shetland Islands. Polar Biology , 36 (6), 871-883.

Wilson, N. G., Hunter, R. L., Lockhart, S. J., \& Halanych, K. M. (2007). Multiple lineages and absence of panmixia in the "circumpolar" crinoid Promachocrinus kerguelensis from the Atlantic sector of Antarctica. Marine Biology , 152 (4), 895-904. https://doi.org/10.1007/s00227-007-0742-9

Yokobori, S., Kurabayashi, A., Neilan, B. A., Maruyama, T., \& Hirose, E. (2006). Multiple origins of the ascidian- Prochloron symbiosis : Molecular phylogeny of photosymbiotic and non-symbiotic colonial ascidians inferred from 18S rDNA sequences, 40 , 8-19. https://doi.org/10.1016/j.ympev.2005.11.025

Yund, P. O., Collins, C., \& Johnson, S. L. (2015). Evidence of a native northwest atlantic COI haplotype clade in the cryptogenic colonial ascidian Botryllus schlosseri. Biological Bulletin ,228 (3), 201-216. https://doi.org/10.1086/BBLv228n3p201

Zachos, J. C., Pagani, M., Sloan, L., Thomas, E., \& Billups, K. (2001). Trends, Rhythms, and Aberrations in Global Climate 65 Ma to Present: Discovery Service para UNAM. Science , 292 (5517), 686-693. https://doi.org/10.1126/science.1059412

Zhou, Y., Duvaux, L., Ren, G., Zhang, L., Savolainen, O., \& Liu, J. (2017). Importance of incomplete lineage sorting and introgression in the origin of shared genetic variation between two closely related pines with overlapping distributions. Heredity , 118 (3), 211-220. https://doi.org/10.1038/hdy.2016.72

Zigler, K. S., McCartney, M. A., Levitan, D. R., \& Lessios, H. A. (2005). Sea urchin bindin divergence predicts gamete compatibility.Evolution , 59 (11), 2399-2404.

\section{Data Accessibility}

Sequence data can be found in NCBI GenBank (https://www.ncbi.nlm.nih.gov/genbank/), 18S entire sequences with accession numbers MN700311 - MN700622, COI entire sequences and protein traduction with accession numbers MN714370 - MN714622. Morphological and genetic data can be found in PANGEA (https://www.pangaea.de/), doi: https://doi.org/10.1594/PANGAEA.909707.

\section{Authors' contributions}

RS obtained the samples from field for genetic analysis. NS sampled the animals for morphological analysis. MR carried out genetic laboratory work and analysis of genetic data. AT and MR analysed the morphology of the specimens, AT run the statistical morphological analysis form and contributed to the discussion of morphological data. $\mathrm{CH}$ provided laboratory space and reagents. MR wrote the manuscript. $\mathrm{RS}$ and $\mathrm{CH}$ provided supervision and research advice. All authors read and approved the final manuscript.

\section{Legends}

Fig. 1. Haplotype network of COI mitochondrial gene. Areas of the circles are proportional to the number of individuals. Each circle represents a haplotype, dots between haplotypes symbolize mutational steps.

Fig. 2. Phylogenetic trees obtained with Maximum Likelihood and Bayesian Inference approaches. Left, phylogeny constructed with the mitochondrial marker COI. Right, phylogeny constructed with the nuclear marker 18S. Only nodes supported by bootstrap value [?] 51 and posterior probability [?] 0,86 are reported. Mirrored pattern of branching clades is observed, dotted lines indicate the only two samples that do not show this congruent pattern. In red group A, in blue group B defined by ABGD species delimitation analysis and the haplotype network of COI. 
Fig. 3. Species distribution along the Antarctic Peninsula. Each circle represents a sampling station, in red the proportion of $C$. verrucosa $s p$. $A$, in blue the proportion of $C$. verrucosa $s p$. B, in grey no A/no B (basal branch). Numbers represent sample size.

Fig. 4. Photos. a) specimen with basal disc, b) specimen without basal disc. To the right (c and d) underwater photos taken by Cristian Lagger, in the benthos assemblage of Potter Cove where high diversity of morphological features is observed in C. verrucosa sensu lato.
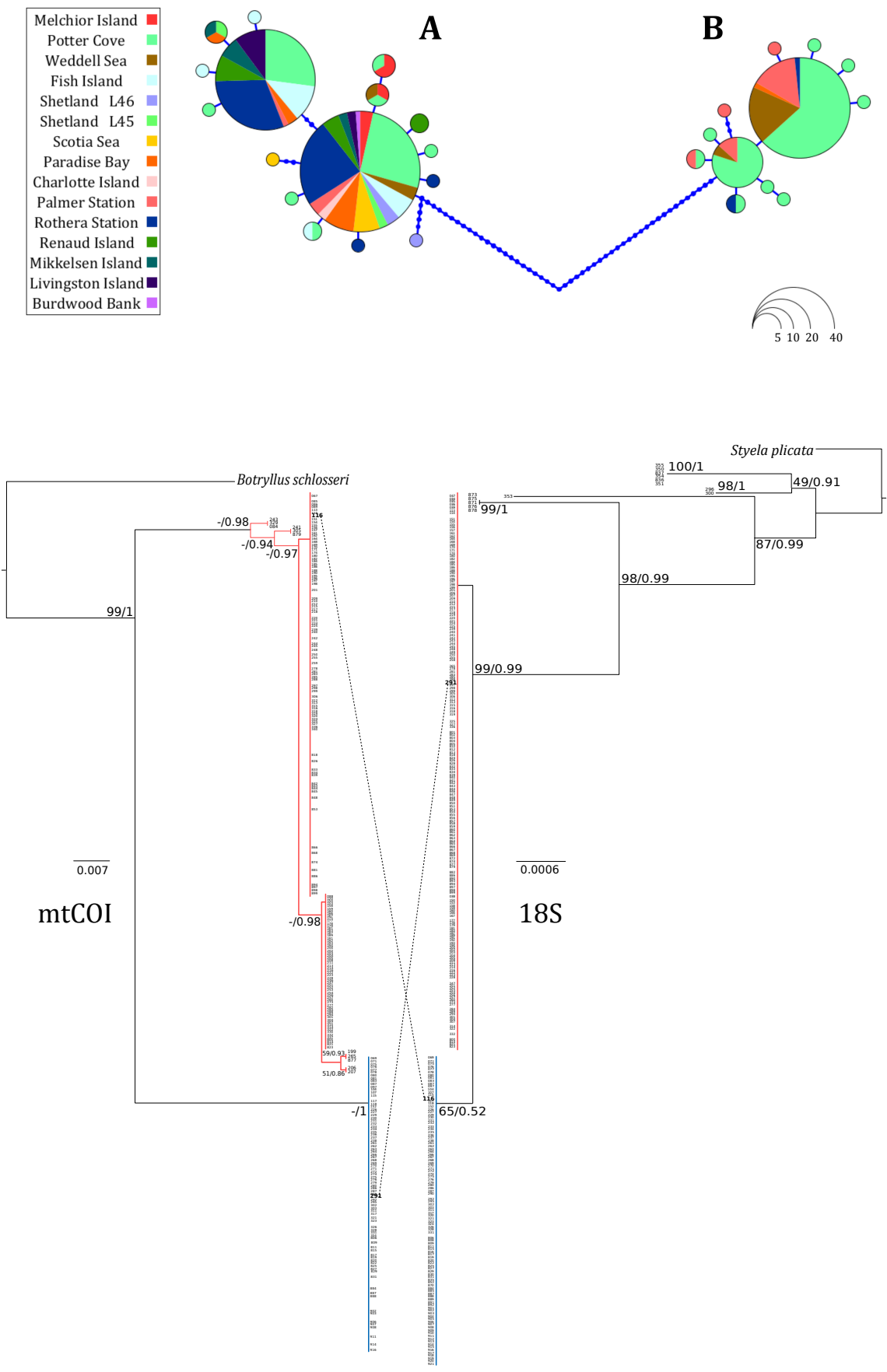


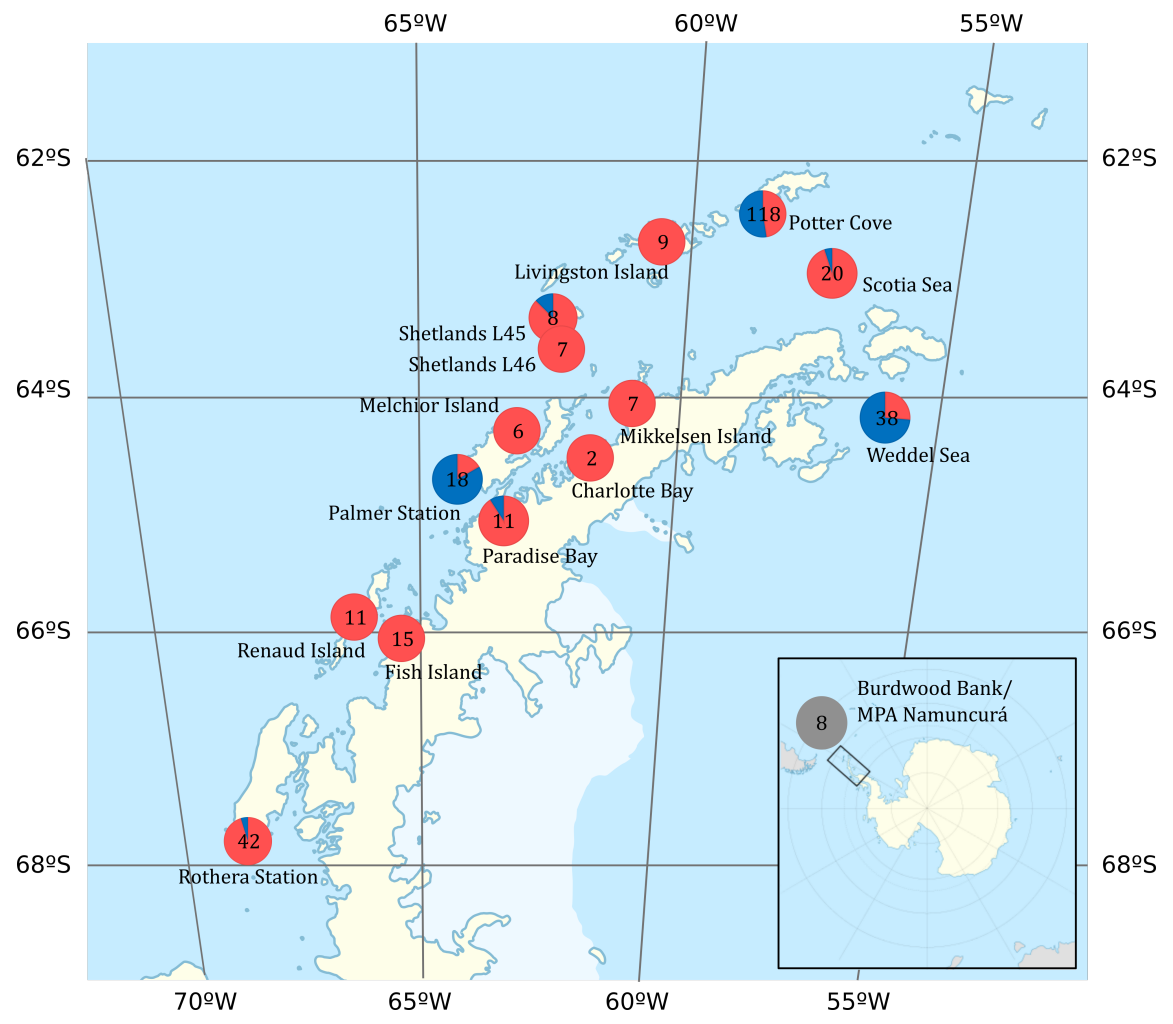




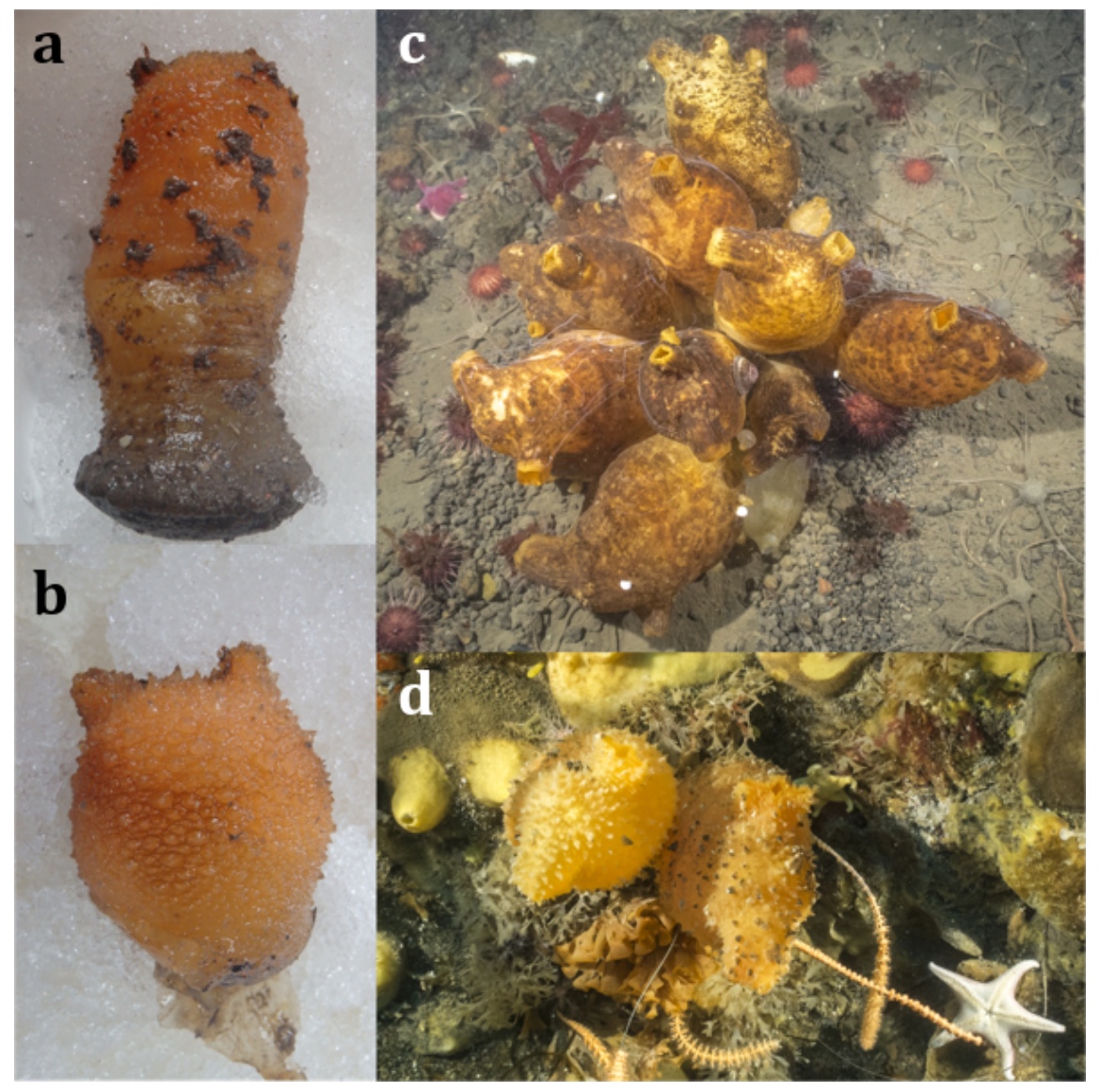

